\title{
Glycogenome expression dynamics during mouse C2C I 2 myoblast differentiation suggests a sequential reorganization of membrane glycoconjugates
}

\author{
Mathilde Janot, Aymeric Audfray, Céline Loriol, Agnès Germot, \\ Abderrahman Maftah* and Fabrice Dupuy
}

Address: INRA, UMR 1061 Unité de Génétique Moléculaire Animale, Université de Limoges, Faculté des Sciences et Techniques, 123 Avenue A. Thomas, 87060 Limoges, France

Email: Mathilde Janot - mathilde.janot@etu.unilim.fr; Aymeric Audfray - aymeric.audfray@etu.unilim.fr;

Céline Loriol - celine.loriol@etu.unilim.fr; Agnès Germot - agnes.germot@unilim.fr; Abderrahman Maftah* - abderrahman.maftah@unilim.fr; Fabrice Dupuy - fabrice.dupuy@unilim.fr

* Corresponding author

This article is available from: http://www.biomedcentral.com//47/-2/64//0/483

(C) 2009 Janot et al; licensee BioMed Central Ltd.

This is an Open Access article distributed under the terms of the Creative Commons Attribution License (http://creativecommons.org/licenses/by/2.0), which permits unrestricted use, distribution, and reproduction in any medium, provided the original work is properly cited.

\begin{abstract}
Background: Several global transcriptomic and proteomic approaches have been applied in order to obtain new molecular insights on skeletal myogenesis, but none has generated any specific data on glycogenome expression, and thus on the role of glycan structures in this process, despite the involvement of glycoconjugates in various biological events including differentiation and development. In the present study, a quantitative real-time RT-PCR technology was used to profile the dynamic expression of 375 glycogenes during the differentiation of $\mathrm{C} 2 \mathrm{Cl} 2$ myoblasts into myotubes.

Results: Of the 276 genes expressed, 95 exhibited altered mRNA expression when $\mathrm{C} 2 \mathrm{Cl} 2$ cells differentiated and 37 displayed more than 4-fold up- or down-regulations. Principal Component Analysis and Hierarchical Component Analysis of the expression dynamics identified three groups of coordinately and sequentially regulated genes. The first group included 12 down-regulated genes, the second group four genes with an expression peak at $24 \mathrm{~h}$ of differentiation, and the last $2 \mathrm{I}$ upregulated genes. These genes mainly encode cell adhesion molecules and key enzymes involved in the biosynthesis of glycosaminoglycans and glycolipids (neolactoseries, lactoseries and ganglioseries), providing a clearer indication of how the plasma membrane and extracellular matrix may be modified prior to cell fusion. In particular, an increase in the quantity of ganglioside $G_{M 3}$ at the cell surface of myoblasts is suggestive of its potential role during the initial steps of myogenic differentiation.
\end{abstract}

Conclusion: For the first time, these results provide a broad description of the expression dynamics of glycogenes during $\mathrm{C} 2 \mathrm{Cl} 2$ differentiation. Among the 37 highly deregulated glycogenes, 29 had never been associated with myogenesis. Their biological functions suggest new roles for glycans in skeletal myogenesis. 


\section{Background}

Myogenesis is a complex process which leads muscle progenitor cells to proliferate and then differentiate into myotubes. This process is strongly controlled by the spatio-temporal expression of myogenic regulatory factors (MRFs) - MyoD, Myf5, myogenin and Mrf4 (or Myf6) $[1,2]$ - and by several transcription factors of the myocyte enhancer factor-2 (MEF2) family [3]. Their expression defines different stages in the myogenic process: myoblast proliferation, cell-cycle withdrawal, cell fusion to form myotubes, and the maturation of myotubes into myofibers. MRFs are members of the bHLH (basic Helix-LoopHelix) protein family [4]. They cooperate with MEF2 transcription factors to mediate the transcription of musclespecific genes [5]. bHLH proteins also form heterodimers with E proteins $[6,7]$, enabling binding to the E-box consensus DNA sequence [8] and the transcription of specific skeletal muscle genes, such as the myosin heavy chain gene [9].

As well as myogenic factors, myogenesis involves other molecular actors such as embryonic fibroblast growth factor (eFGF), cadherins, members of the cadherin-associated immunoglobulin superfamily such as CDO (CAM (Cell Adhesion Molecule)-related/down-regulated by oncogenes), BOC (brother of $\underline{\text { CDO) }}$ [10], neogenin [11] and p38 MAP kinase [12]. These are the classic molecules involved in cell interactions and signaling. In order to monitor the expression of these actors, several studies have exploited the development of high-throughput gene expression profiling using microarrays and proteomic approaches. Recent microarray studies on C2C12 cells, mouse myoblasts that can differentiate into myotubes, have afforded a broad molecular description of myogenesis and identified sets of genes that display transcriptional variations in expression between proliferating and differentiating cells [13-16]. These studies identified some genes, as Zfp-51 and Ptger4, which were not previously associated with skeletal myogenic differentiation. Some proteomics studies on developing myotubes have partially confirmed and completed these microarray-based studies by providing evidence for the involvement of transcription regulators, signaling factors, phospho-proteins and adhesion molecules, as well as novel non-characterized proteins (Riken clones and unnamed proteins) in skeletal muscle development and contractility $[17,18]$.

The plasma membrane and extracellular matrix (ECM) of myoblasts, like those of other eukaryotic cells, are rich in glycoproteins and glycolipids. Despite all the data generated by transcriptomic and proteomic studies, little information is available on the role of glycoconjugates in myogenesis. The principal reason for this lies in the weak expression of glycogenes which is hardly detectable using pan-genomic microarrays. Nevertheless, some proteogly- cans of the ECM, e.g. syndecans, have been shown to play different roles in myogenesis $[19,20]$. Inhibition of their synthesis halts myoblast proliferation and fusion independently of the expression of the myogenic bHLH factor. In the same way, blocking $N$-glycan synthesis impairs myoblast fusion [21] and the in vivo invalidation of Mgat1, a gene involved in the synthesis of complex N-glycans, generates mouse embryo death in utero [22]. Conversely, NCAM1 O-glycosylation promotes myoblast fusion [23,24]. Glycolipids also play key roles in cell differentiation $[25,26]$. They appear to be involved in muscle development, since their membrane levels are altered during G7 and G8 myoblast fusion, with an increase in gangliosides and neutral glycolipid synthesis [27]. In other myogenic cell lines, changes have been observed in the activities of the glycosyltransferases that contribute to glycolipid synthesis [28].

In order to clarify the potential roles of glycosylation in myogenesis, quantitative real-time RT-PCR was used to analyze the expression of 375 glycogenes (that account for more than $60 \%$ of the glycogenome) in differentiating mouse C2C12 cells. Seventy-four percent of the genes (276 genes) were expressed during C2C12 cell differentiation: 181 of them were invariant while 37 displayed upor down-regulations of more than 4-fold. These genes were clustered in three main groups. The first cluster contained genes with gradually decreasing quantities of transcripts. In the second set of genes, transcript levels reached a maximum at 24-48 $\mathrm{h}$ of differentiation and then decreased, while those in the third cluster increased throughout differentiation. The functions controlled by the clustered genes, as a function of their group, highlighted how the myoblast cell membrane and ECM could be modified for cell fusion during C2C12 differentiation. For the first time, this study provides a general framework for glycogene expression during the onset of in vitro myogenesis.

\section{Results and Discussion}

The combined use of cell lines and microarrays offers a major opportunity to study gene expression patterns and/ or dynamics during different physiological and pathological processes. However, the substantial findings generated by the use of pangenomic microarrays have generally been difficult to interpret in terms of the gene regulation controlling biological functions. In this study, we chose to explore the expression dynamics of just one part of the mouse genome, called the 'glycogenome', in the context of myogenesis. For this purpose, we first of all standardized the experimental conditions for the differentiation of C2C12 (a mouse myogenic cell line), and analyzed the expression of myogenic markers by quantitative real-time RT-PCR. The expression of 375 glycogenes was then monitored in differentiating $\mathrm{C} 2 \mathrm{C} 12$ cells using quantitative 
real-time RT-PCR with TLDA (TaqMan Low Density Array, see Methods section). Highly deregulated genes were next clustered as a function of their expression profiles. Their functions were analyzed and used to suggest new roles for glycoconjugates in myogenic differentiation.

\section{The expression of MRF and marker genes is consistent with C2CI 2 cell differentiation}

When cultured in vitro, C2C12 myoblasts start to differentiate following serum deprivation. The first myotubes appeared 48 hours after serum starvation and a maximum of mature multinucleated cells was obtained after 11 days in the differentiation medium (Figure 1A). Expression levels of the four MRFs (Mrf4, Myf5, MyoD and myogenin) and four marker genes (Csrp3, Hes6, Mef2a and Mef2d) known for their involvement in myogenic differentiation [29-31], were determined by quantitative real-time RTPCR at different time points following the induction of C2C12 differentiation.

$M y o D, M y f 5$ and myogenin genes were expressed throughout $\mathrm{C} 2 \mathrm{C} 12$ differentiation (Figure $1 \mathrm{~B}$ ). MyoD mRNA levels only changed slightly, regardless of the time elapsing after the start of differentiation. Beyond $\mathrm{t}=48 \mathrm{~h}$, the expression of $M y f 5$ decreased more than two-fold and remained down-regulated, while the myogenin gene was up-regulated ( 100-fold). For Mrf4, transcripts were only detected at $\mathrm{t}=192 \mathrm{~h}$. Therefore, the expression profiles of myogenic regulatory factors during C2C12 differentiation were in agreement with their expression patterns (top diagram inset in Figure 1B) described in the literature $[15,16,32,33]$.

Expression of the muscle transcription factors Mef $2 a$ and Mef $2 d$ increased as from $6 \mathrm{~h}$ of differentiation to reach 60fold for Mef $2 a$ and 3.4-fold for Mef $2 d$ at the end of the experiment (Figure 1C). Their expression was in line with their myogenic activator roles [29]. Interestingly, the increase in Hes6 expression started at $\mathrm{t}=6 \mathrm{~h}$ of differentiation and reached 6.5-fold after $72 \mathrm{~h}$. As demonstrated elsewhere [31], this last result argued in favor of Hes6 involvement at the onset of $\mathrm{C} 2 \mathrm{C} 12$ differentiation and more generally of the myogenic process. Unlike the Hes and Mef genes, Csrp3 expression was first detected at $\mathrm{t}=18$ $\mathrm{h}$ of differentiation and increased to reach a peak at $\mathrm{t}=$ 120 h (Figure 1C). The expression profile of Csrp3, encoding the LIM protein, correlated with its activator function of $\mathrm{C} 2 \mathrm{C} 12$ differentiation. Indeed, it has been showed that LIM protein is not necessary for myoblast proliferation but plays a key role in upcoming myogenic differentiation [30]. Thus, the transcriptional expression profiles of both myogenic marker genes and MRFs genes attested to the accurate time course of $\mathrm{C} 2 \mathrm{C} 12$ differentiation.

\section{Most glycogenes are expressed during the onset of $\mathrm{C2CI} 2$ differentiation}

The glycogenome refers to all genes involved in glycosylation. It includes $\sim 600$ genes and accounts for $\sim 2$ percent of the mouse genome. The expression of 375 glycogenes was analyzed during the first $72 \mathrm{~h}$ of C2C12 differentiation, when the first myotubes are formed. These 375 glycogenes account for more than $60 \%$ of the mouse genes known to be related to glycosylation (Table 1 ). The proteins encoded by these genes belong to glycosyltranferases, glycosidases, lectins, sulfotranferases or proteins involved in sugar metabolism or transport [see Additional file 1]. Given the known weak expression of most glycogenes, their expression patterns were determined by quantitative real-time RT-PCR using the TLDA technology which allows the simultaneous analysis of 375 selected genes [see Additional file 2].

Three-quarters of the genes analyzed were expressed (Table 1): 276 genes displayed significant quantities of transcripts $(\mathrm{Ct} \leq 33)$ during at least one point of the differentiation time course. Among the 375 glycogenes of this study, 202 genes were also analyzed in Tomczak et al. study [16]. The microarray and TLDA approaches gave similar results for 91 genes, 43 were expressed and 48 unexpressed. For the remaining common genes (111), only TLDA revealed significant expression levels. This could be explained by the methodologies employed, insofar as microarray techniques are less precise and sensitive than quantitative real-time RT-PCR [34].

Among the genes expressed, 34\% had a minimum 2-fold modification of their expression for at least one kinetic time, and $10 \%$ displayed a variation of at least 4 -fold (Table 1). The significant number of glycogenes thus regulated underlined the critical function of glycosylation in this differentiation process. Lectin genes appeared to be regulated preferentially, because only $57 \%$ of them were expressed, compared to $73 \%$ or more for the other gene families. Within each glycogene family, it is interesting to note that no correlation was observed between the number of genes analyzed and the number of those regulated. Indeed, glycosyltransferase genes accounted for about $40 \%$ of analyzed genes and only $11 \%$ of them displayed an mRNA variation of more than 4 -fold. At the same time, $\sim 50 \%$ of lectin and sulfotransferase genes, representing $\sim 27 \%$ and $\sim 6 \%$ of analyzed genes respectively, were significantly modified in terms of their expression. In addition, no glycogene sub-family, such as fucosyltransferases or sialyltransferases, was preferentially repressed or expressed.

Genes displaying more than 4-fold variation (37 genes) were distributed into four groups according to their glycofamily (Table 1). The first group included lectin and sul- 
A)
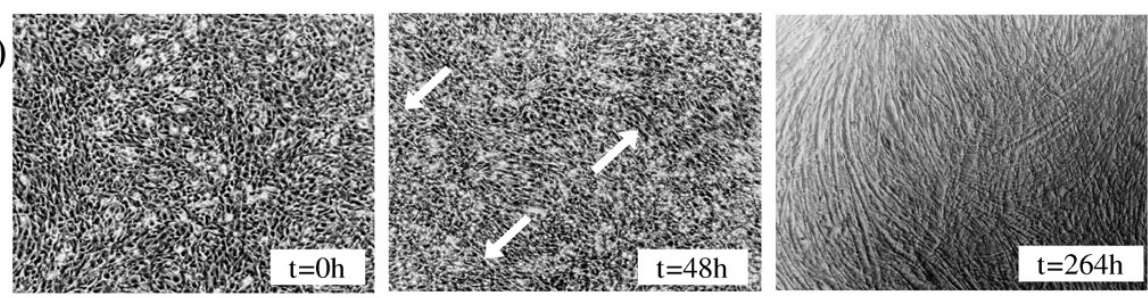

B)

1000

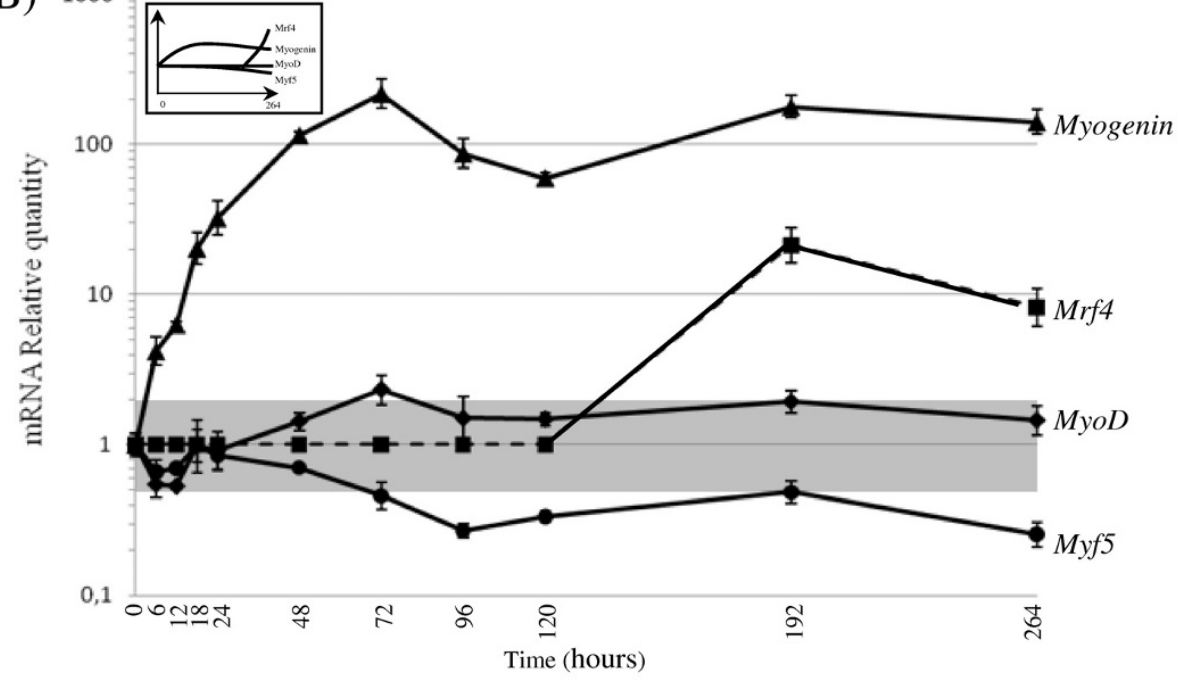

C)

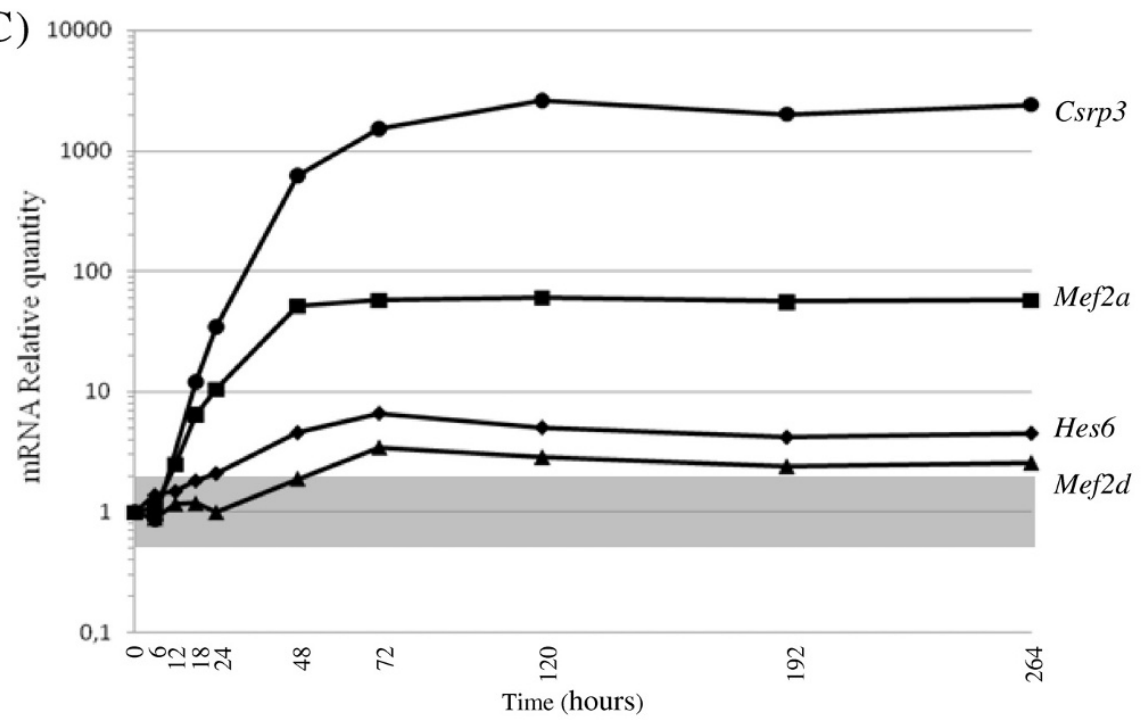

Figure I

Time course of $\mathrm{C} 2 \mathrm{CI} 2$ differentiation. (A) $\mathrm{C} 2 \mathrm{Cl} 2$ cells were placed in differentiation medium when culture reached $80 \%$ of confluence $(t=0 \mathrm{~h})$. After 48 hours, the first myotubes, indicated by arrows, had clearly formed and after II days $(\mathrm{t}=264$ h), most of the cells had merged into myotubes. C2CI2 RNA was extracted at several differentiation time points and tested for the presence of (B) mRNA from the myogenic markers Myf5, MyoD, Myogenin and Mrf4 and (C) mRNA from the musclespecific markers Csrp3, Hes6, Mef2a and Mef2d. Transcription levels are expressed as relative quantities (RQ) compared to the initiation of differentiation $(t=0 \mathrm{~h})$. The grey area includes no significant variations $(\mathrm{RQ}< \pm 2)$. For $(\mathrm{B})$, standard deviations were calculated on three separate experimental values. No significant transcriptional expression of Mrf4 was detected before $t$ $=192 \mathrm{~h}(\mathrm{Ct}>33$, dotted line). The top inset presents the standard expression patterns of the four myogenic markers Myf5, MyoD, Myogenin and Mrf4 as found in the literature. 
Table I: Data summary of Mus musculus glycogene expression during $\mathrm{C} 2 \mathrm{Cl} 2$ differentiation.

\begin{tabular}{|c|c|c|c|c|c|}
\hline Protein function & $\begin{array}{l}\text { Number of known } \\
\text { genes' }\end{array}$ & $\begin{array}{l}\text { Number of ana- } \\
\text { lyzed genes }^{2}\end{array}$ & $\begin{array}{l}\text { Number of } \\
\text { expressed genes }\end{array}$ & $\begin{array}{l}\text { Genes with } 2 \times \text { up- or } \\
\text { down-regulation } 4\end{array}$ & $\begin{array}{l}\text { Genes with } 4 \times \text { up- or } \\
\text { down-regulation } 4\end{array}$ \\
\hline Glycosyltransferase & 209 & I 46 (70\%) & 108 (74\%) & 37 (34\%) & $12(11 \%)$ \\
\hline Glycosidase & 75 & $53(7 \mid \%)$ & 47 (89\%) & $8(17 \%)$ & $2(4 \%)$ \\
\hline Sugar carrier & 34 & $26(76 \%)$ & $19(73 \%)$ & 7 (37\%) & $3(16 \%)$ \\
\hline Translocase & 2 & $2(100 \%)$ & $2(100 \%)$ & $0(0 \%)$ & $0(0 \%)$ \\
\hline Sugar metabolism & 28 & $24(86 \%)$ & $23(96 \%)$ & $4(17 \%)$ & $0(0 \%)$ \\
\hline Lectin & 193 & 102 (53\%) & 58 (57\%) & $29(50 \%)$ & $15(26 \%)$ \\
\hline Sulfotransferase & 53 & $22(42 \%)$ & $19(86 \%)$ & $10(53 \%)$ & $5(26 \%)$ \\
\hline Total & 594 & 375 (63\%) & 276 (74\%) & 95 (34\%) & $37(10 \%)$ \\
\hline
\end{tabular}

IThe number of known genes was determined in the MGI database [6I] according to their functions.

2The number of analyzed genes, except for the sulfotransferase family, corresponded to assays available from the manufacturer. For sulfotransferase genes, 22 probes were chosen from the 35 available. Values in brackets indicate percentages of analyzed genes compared to known genes.

${ }^{3} \mathrm{Number}$ of expressed genes corresponded to significantly expressed genes for at least one kinetic point according to their mRNA quantification by qRT-PCR $(\mathrm{Ct}<33)$. Values in brackets indicate percentages of expressed genes compared to analyzed genes.

$4 U_{p}$ - and down-regulations correspond to variations in transcript quantity with a minimum factor of 2 or 4 . Values in brackets correspond to percentages of deregulated genes compared to expressed genes.

fotransferase genes $(26 \%$ of them with significant mRNA variations), the second contained glycosyltransferase and sugar carrier genes (11-16\% deregulated), the third included glycosidase genes (only $4 \%$ of genes deregulated), and the final group comprised translocase and sugar metabolism genes in which no gene displayed a variation in mRNA expression. Thus, a large proportion of the modifications to glycogene expression that occurred during $\mathrm{C} 2 \mathrm{C} 12$ differentiation mainly seemed to affect proteins giving rise to the glycans or lectins required for cell contacts. These results are consistent with the cellular events involved in myotube formation, i.e. cell interactions and fusions.

Among the genes analyzed, 99 were poorly or not expressed. Their corresponding mRNA were not detected $(\mathrm{Ct}=40)$ or not significantly quantified $(\mathrm{Ct}>33)$. These genes encoded proteins involved in physiological processes unrelated to myogenesis. For example, Has3 encodes a hyaluronan synthase which is active in hyaluronan/ hyaluronic acid synthesis and known to be involved in the inflammatory response [35], and Icam2 encodes a lectin which mediates adhesive interactions during the immune response.

\section{Nearly half of analyzed glycogenes could be cell homeostasis genes}

Among the 276 genes expressed, 181 were invariantly transcribed (Table 1). These constitutively expressed genes could be divided into three sets, according to their functions. The first set corresponded to genes involved in cell homeostasis, the second to genes involved in myogenic cell homeostasis and the third to myogenic genes that could probably undergo a late modification to their expression. In this respect, most of the genes encoding proteins involved in $\mathrm{N}$-glycan precursor synthesis and present on our mouse glycogenome TLDA were homeostasis cell genes and were constitutively expressed. Alg2, Alg3, Alg9, Alg12 (mannosyltransferase genes) and Alg6 (a glucosyltransferase gene), which are responsible for $N$ glycan precursor synthesis, were expressed without any significant variations. This was also the case for Dpia3 (or Erp57), an ER chaperone-encoding gene involved in disulfide bond formation [36]. The second set of genes, although constitutively expressed during the first $72 \mathrm{~h}$ of differentiation, could have crucial functions at all stages of myogenesis. The myogenic factor $M y o D$, or the sialidase gene Neu3 are representative of this group [37]. Finally, the expression of the third set of genes may be modified after $72 \mathrm{~h}$ of differentiation and be required for later stages of myogenesis. For example, the expression of Pomt1, encoding an O-mannosyltransferase which is known to glycosylate the muscle membrane protein $\alpha$-dystroglycan linking cytoskeleton actin to ECM components, could be tardily up-regulated [38].

\section{Glycogenes with significant mRNA variations are sequentially expressed}

On the 95 regulated genes, 37 whose expression levels were modified more than 4 -fold were retained for further analyses. In order to obtain a global vision of their expression profiles, Principal Component Analysis (PCA) was performed. Its efficiency was excellent since $~ 89 \%$ of information in the data set was recovered on the first ordinate ( $~ 70 \%$ on component 1 and $\sim 19 \%$ on component 2 ). The localization of each gene in the Figure indicates its expression as a function of differentiation times ( 6 to 72 $\mathrm{h})$, compared with the precursor state at $\mathrm{t}=0 \mathrm{~h}$ of differentiation (Figure 2A). The position of a gene in the same direction as a vector indicates an increase of expression. By 


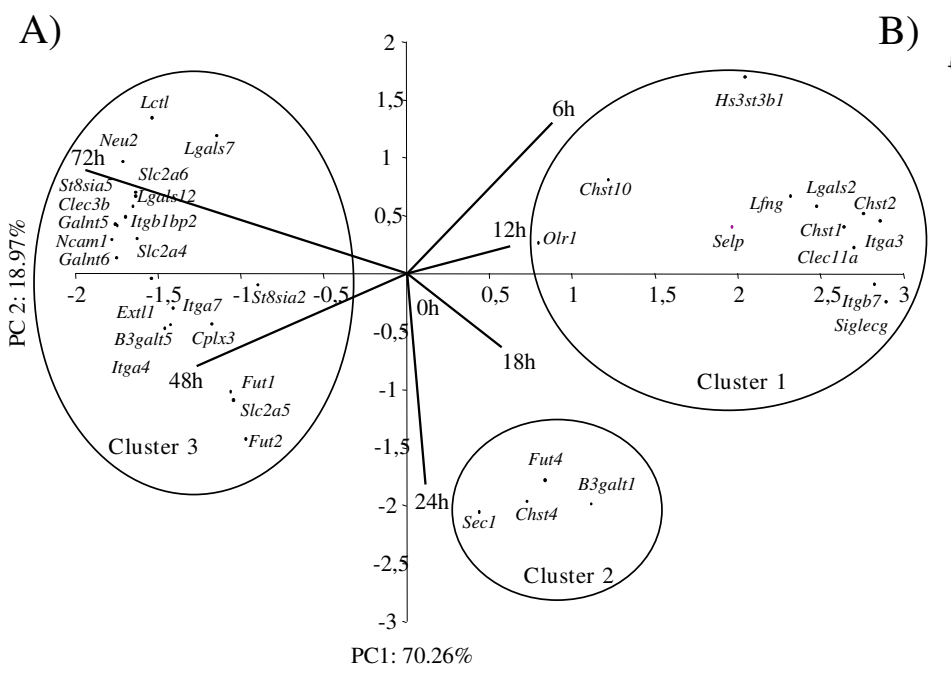

B) Similarity

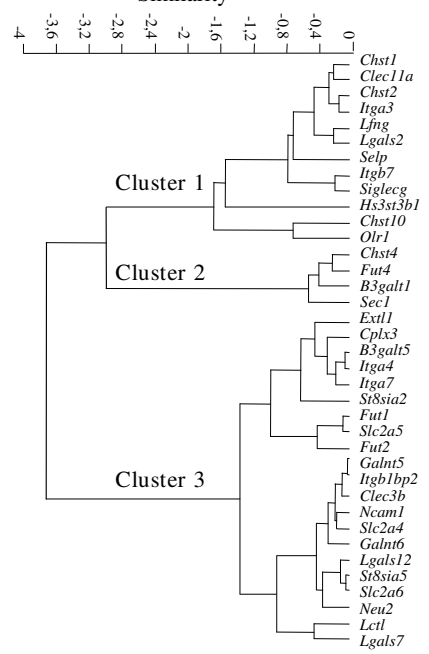

C)

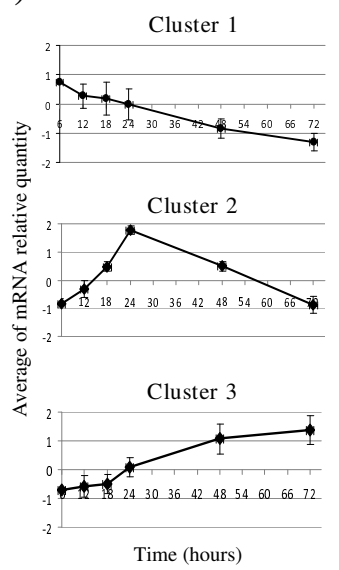

Figure 2

Expression dynamics of up- and down-regulated glycogenes during the onset of mouse $\mathrm{C} 2 \mathrm{CI} 2$ differentiation. (A) According to their expression profiles, the 37 glycogenes expressed with more than-4 fold variations were analyzed using a principal component analysis (PCA). Gene expression profiles in differentiated $\mathrm{C} 2 \mathrm{Cl} 2$ cells were plotted according to the plan defined by the two first principal components, $\mathrm{PCl}$ and $\mathrm{PC2}$. The $\mathrm{PCl}$ axis corresponds to the gradient of gene expression occurring in the time course. Each vector, numbered 0 to $72 \mathrm{~h}$, represents the orientation for genes increasing along each time. In the opposite direction to these vectors are genes whose expression decreased. (B) A dendrogram representation of the hierarchical cluster analysis of the 37 gene expression levels shows three distinct clusters. (C) Expression dynamics of glycogenes were modeled according to their membership cluster.

contrast, the position of a gene in the opposite direction to a vector means that the gene was down-regulated. Because of their reduced sizes, $12 \mathrm{~h}$ and $18 \mathrm{~h}$ vectors were only weakly informative.

Gene clustering was performed using the Euclidean distances calculated with their coordinates on the first plan of PCA. This clearly highlighted three groups (Figure 2B). The first contained 12 genes, the second four and the third 21 . The myogenic marker $M y f 5$ was classified in cluster 2, $M y o D$ and myogenin in cluster 3 (data not shown); Mrf4 was not clustered since it was not expressed during the first $72 \mathrm{~h}$ of differentiation. mRNA levels in the cluster 1 displayed a general tendency to decrease that was more pronounced towards the end of the time course (Figure 2C). Cluster 2 included genes with a peak mRNA expression at $24 \mathrm{~h}$ of differentiation. Genes in cluster 3 had expression profiles opposite to those of cluster 1 because these expressions increased and became more important at the end of the time course (Figure 2C).

The 37 highly regulated glycogenes were examined according to the activity/function of the enzymes they encode. Only their functions linked to myogenesis were considered (Figure 3). Functions unknown or unrelated to myogenesis, such as intracellular transport, were grouped in "other function". In the light of the literature, several functions could be assured by one protein. Genes in cluster 1 encoded proteins mainly involved in cell adhesion and interaction, GAG biosynthesis and signal transduction. The down-regulation of most of them could be required for the early mechanisms of myogenesis, especially for the switch from a proliferative to a quiescent state and then to a differentiated state. The four genes in cluster 2 were mainly involved in glycosphingolipid and GAG biosynthesis (Figure 3). These functions suggest early rearrangements of the plasma membrane and ECM, leading to the first fusion events. Among the up-regulated genes in cluster 3, some genes were also involved in glycosphingolipid biosynthesis while the others encoded proteins that were mostly implicated in cell adhesion and interaction and in intracellular biological functions. These functions were consistent with the fusion events leading to myotube formation and maturation beyond $48 \mathrm{~h}$ of serum deprivation.

With regards the sequential expression of $\geq 4$-fold variant glycogenes and the function of encoded proteins, the early differentiation of $\mathrm{C} 2 \mathrm{C} 12$ cells seemed mainly to require: (i) the specific expression of molecules involved in cell signaling and a modification to ECM composition, (ii) the expression of CAMs, and (iii) qualitative and/or quantitative modifications to plasma membrane glycoconjugates. 


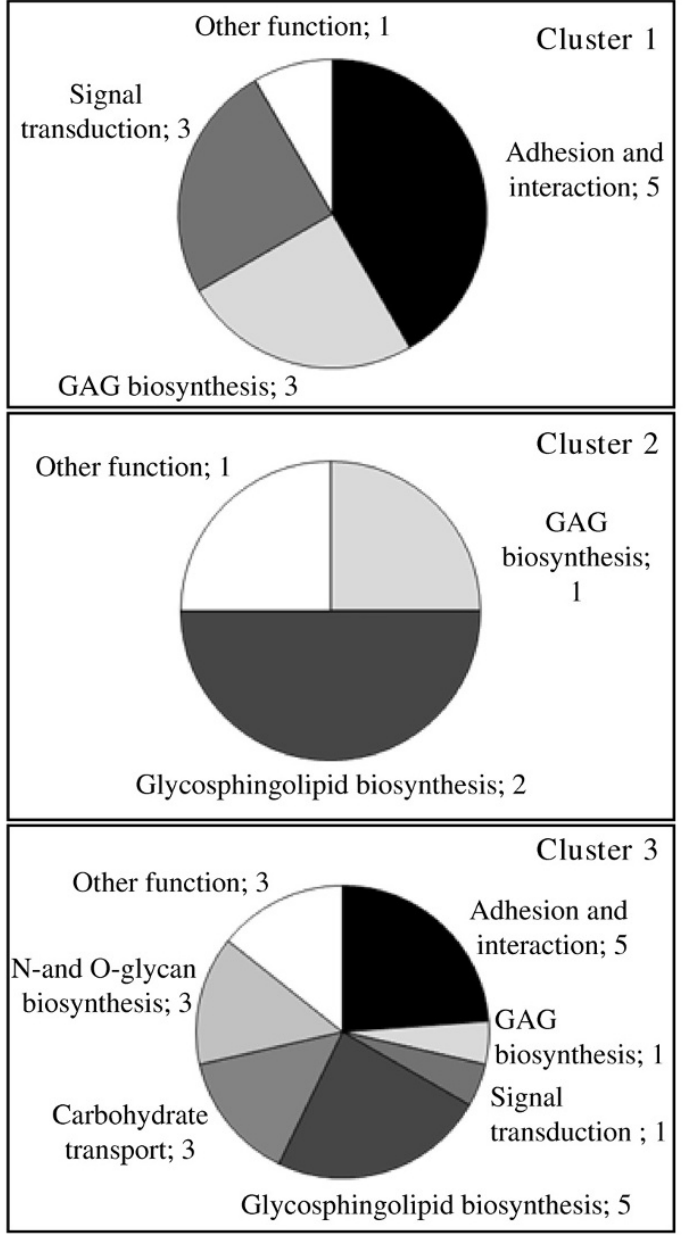

Figure 3

Cell functions in which regulated glycogenes are involved. The function assigned to each gene was extracted from the Kegg Pathway database [64]. Numbers indicate how many genes are concerned for each function, one gene being able to be involved in different processes. "Other functions" corresponds to functions unrelated to developmental processes, such as exocytosis and apoptosis.

\section{Cell signaling and GAGs sulfation contribute to the initiation of myogenesis}

The functions assured by some down-regulated genes in cluster 1 suggested an involvement of cell signaling in myogenic differentiation. The commitment of $\mathrm{C} 2 \mathrm{C} 12$ cells to the myogenic or adipogenic lineage is controlled by specific transcription factors. Myogenesis is regulated by MRFs [4], while adipogenesis is controlled by PPAR- $\gamma$ and the C/EBP families of transcription factors $[39,40]$. The Olr1 gene encodes a lectin which is activated by PPAR- $\gamma$ signaling [41]. The down-regulation of Olr1 is consistent with the commitment of $\mathrm{C} 2 \mathrm{C} 12$ to myogenic differentiation. Lfng is an enzyme that elongates $O$-fucose on some EGF-like domains of the Notch receptor. It belongs to the Fringe family [42] and acts as a modulator of the Notch signaling pathway [43]. It also influences cell fate during embryonic development [44]. Given the involvement of Notch in the myogenic process [45], Lfng down-regulation in differentiating $\mathrm{C} 2 \mathrm{C} 12$ cells argues for the involvement of Lfng in myogenic differentiation. Interestingly, among the up-regulated genes in cluster 3, Lgals12 encoded the galectin-12 which is required for adipogenic signaling and adipocyte differentiation [46]. This gene is indeed weakly expressed at early stages, but its important transcriptional induction beyond $48 \mathrm{~h}$ of differentiation suggests, for the first time, its later implication in myogenesis.

GAGs are known to have many biological functions, including cell adhesion, migration and signaling [47]. Three sulfotransferase genes from cluster 1 (Chst1, Chst2 and $H s 3 s t 3 b 1$ ) are known for GAG sulfation. Chst 1 and Chst 2 are involved in the sulfation of keratan GAG and Hs3st3b1 in that of heparan GAG. Because Hst3st3b1 is the only gene in cluster 1 which was up-regulated at an early stage (Table 2), heparan GAG could become preferentially sulfated. Moreover, the Extl1 gene in cluster 3 encoded a glycosyltransferase that contributes to heparan/ heparin sulfate biosynthesis. Thus when C2C12 cells differentiate, they seem to undergo a switch from the sulfation of keratan GAG to the predominant sulfation of heparan GAGs. Such a modification has not previously been reported in myogenesis and it could contribute to the activation of myogenesis. Keratan sulfate GAG may have anti-adhesive properties [48] that are obviously incompatible with up-coming myoblast fusion events during myogenic differentiation.

\section{CAMs, glycosphingolipids and glycoproteins of the C2CI2} plasma membrane appeared to be reshaped for cell fusion Myoblast fusion into myotubes requires cell interactions. Ten highly regulated glycogenes are involved in cell adhesion (Figure 3). Among the genes in cluster 1, four encoded lectins (Itga3, Itgb7, Siglecg and Selp) and one a sulfotransferase (Chst10). These five genes have been described in different developmental processes. For example, Itg $\alpha 3$ associated with Itg $\beta 1$ have been shown to mediate the migration of endothelial cells and angiogenesis [49]. In the present case, the down-regulation of Itg $\alpha 3$ may have been linked to the arrest of myoblast migration and proliferation. In addition, five lectin genes encoding for three integrins (Itg $\alpha 4$, Itg $\alpha 7$ and $\operatorname{Itg} \beta 1 \mathrm{bp} 2$ ), one galectin (Lgals7) and Ncam1, belonged to up-regulated genes (Cluster 3). Most of them have important functions in myogenesis: NCAM1 in myoblast fusion [23,24], melusin (encoded by Itgb1bp2) in the maturation and/or organization of muscle cells [50], and Itg $\alpha 7$ (with Itg $\beta 1$ ) in myogenesis $[51,52]$. Up-regulation of these CAM-encoding 
Table 2: Deregulated glycogenes during the onset of $\mathrm{C} 2 \mathrm{C} / 2$ differentiation.

\begin{tabular}{|c|c|c|c|c|c|c|c|c|c|}
\hline \multirow[b]{2}{*}{ Gene Symbol } & \multirow[b]{2}{*}{ Protein function } & \multirow[b]{2}{*}{ Cluster number } & \multicolumn{7}{|c|}{ mRNA Relative Quantity according to differentiation time } \\
\hline & & & $\mathbf{O} \mathbf{h}$ & $6 \mathrm{~h}$ & $12 \mathrm{~h}$ & $18 \mathrm{~h}$ & $24 \mathrm{~h}$ & $48 \mathrm{~h}$ & $72 \mathrm{~h}$ \\
\hline Lffig & GTase & I & I & -1.86 & -2.19 & -2.36 & -3.04 & -5.18 & -5.53 \\
\hline Clecl Ia & Lectin & I & i & -1.28 & -1.67 & 1.05 & -1.81 & -4.86 & -5.24 \\
\hline Itga3 & Lectin & I & I & 1.25 & -1.15 & -1.14 & $-|.5|$ & -2.55 & -4.17 \\
\hline ltgb7 & Lectin & I & I & -1.27 & -1.38 & -1.52 & -1.46 & $-|0.3|$ & $-27.4 I$ \\
\hline Lgals2 & Lectin & i & i & -1.49 & -2.69 & -2.84 & -3.37 & -6.38 & -10.55 \\
\hline Olrl & Lectin & I & 1 & -3.31 & -5.40 & -8.14 & -6.10 & -8.38 & -8.74 \\
\hline Selp & Lectin & i & i & -4.82 & -7.69 & -10.04 & -9.78 & -15.30 & -38.60 \\
\hline Siglecg & Lectin & I & I & 1.22 & 1.20 & 1.44 & 1.20 & -3.34 & -6.88 \\
\hline Chst I & Sulfotransferase & I & I & -1.22 & 1.38 & -1.52 & -1.95 & -2.61 & -5.20 \\
\hline Chst2 & Sulfotransferase & I & I & 1.02 & -1.70 & -1.70 & -2.20 & -5.54 & -8.52 \\
\hline Chstlo & Sulfotransferase & 1 & 1 & -1.69 & -3.77 & -4.11 & -2.69 & -3.43 & -3.77 \\
\hline$H s 3 s t 3 b l$ & Sulfotransferase & 1 & 1 & 5.85 & 3.35 & 2.67 & 1.27 & 1.11 & 1.57 \\
\hline B3galt I & GTase & 2 & I & 0.81 & 1.29 & 2.01 & 4.87 & 1.69 & 0.68 \\
\hline Fut4 & GTase & 2 & i & 1.25 & 1.19 & 1.87 & 4.31 & 1.87 & 1.06 \\
\hline Secl & GTase & 2 & 1 & -1.69 & 1.22 & 2.35 & 7.21 & 4.04 & -1.37 \\
\hline Chst 4 & Sulfotransferase & 2 & 1 & 0.92 & 1.52 & 2.95 & 6.30 & 2.48 & 1.08 \\
\hline Lctl & Glycosidase & 3 & 1 & 1.15 & -1.88 & -3.04 & -3.10 & 2.01 & 4.12 \\
\hline Neu2 & Glycosidase & 3 & I & 1.00 & -1.18 & 1.10 & 1.00 & 3.63 & 18.97 \\
\hline B3galt5 & GTase & 3 & I & -1.13 & 1.40 & 3.19 & 5.91 & 6.34 & 16.14 \\
\hline Extll & GTase & 3 & I & -1.80 & 1.49 & -2.14 & 1.73 & 46.03 & 9.90 \\
\hline Futl & GTase & 3 & i & -1.14 & 2.16 & 2.20 & 6.11 & 24.61 & 4.70 \\
\hline Fut2 & GTase & 3 & 1 & -2.00 & 1.46 & 1.75 & 5.26 & 5.73 & 3.02 \\
\hline Galnt5 & GTase & 3 & 1 & -1.76 & -7.21 & -7.36 & 2.01 & 3.50 & 25.31 \\
\hline Galnt6 & GTase & 3 & I & -1.25 & 1.20 & 1.08 & 2.24 & 34.32 & 28.52 \\
\hline St8sia2 & GTase & 3 & 1 & 1.90 & 2.09 & 2.18 & 3.05 & 3.11 & 4.08 \\
\hline St8sia5 & GTase & 3 & I & 18.06 & -1.13 & 1.05 & 27.43 & 264.72 & 1345.50 \\
\hline Clec3b & Lectin & 3 & I & -1.89 & -6.66 & -1.56 & -1.22 & 1.64 & 4.84 \\
\hline Cplx3 & Lectin & 3 & 1 & 9.55 & 12.32 & 2.35 & 16.42 & 219.09 & 36.18 \\
\hline $\operatorname{ltga} 4$ & Lectin & 3 & i & 1.23 & 1.74 & 2.32 & 4.57 & $|2.4|$ & 9.28 \\
\hline $\operatorname{ltg} a 7$ & Lectin & 3 & 1 & 1.37 & 1.63 & 1.90 & 2.67 & 4.84 & 4.51 \\
\hline ltgb $\mid b p 2$ & Lectin & 3 & I & -1.01 & 1.46 & -1.75 & 2.10 & 41.75 & 49.78 \\
\hline Lgals / 2 & Lectin & 3 & I & -22.54 & -1.48 & -20.60 & -13.28 & 11.47 & 40.29 \\
\hline Lgals7 & Lectin & 3 & 1 & 2.44 & 2.69 & 1.38 & 1.81 & 3.68 & 6.63 \\
\hline Ncam I & Lectin & 3 & I & -1.10 & -1.04 & 1.09 & $1.4 \mathrm{I}$ & 7.38 & 8.09 \\
\hline SIc2a4 & Sugar carrier & 3 & i & 1.09 & 2.11 & 2.24 & 1.81 & 11.97 & 14.68 \\
\hline Slc $2 a 5$ & Sugar carrier & 3 & I & 1.60 & 2.62 & 5.92 & 14.15 & 10.40 & 11.05 \\
\hline Slc2ab & Sugar carrier & 3 & 1 & 2.28 & 1.55 & 1.23 & 2.28 & |3.7| | & 22.33 \\
\hline
\end{tabular}

Only genes whose expression levels are modified more than 4-fold (bold type) for at least one time course point are presented. Their symbols, functions, PCA clusters and relative quantities of mRNA at each kinetic time point are given.

genes, combined with the down-regulation of the four genes in cluster 1 mentioned above, also suggests a potential switch of CAM during myogenic differentiation.

Cell fusion obviously requires a modification to the quality and quantity of glycans in plasma membrane glycolipids and glycoproteins. Three genes in cluster 2 ( $\beta 3$ GalT1, Fut4 and Sec1) encoded glycosyltransferases implicated in glycosphingolipid biosynthesis (Figure 4). $\beta 3$ GalT1 is responsible for synthesizing the precursor of lactoseries glycolipids. Fut4 and Sec1 are involved in the terminal fucosylation of lacto and/or neo-lactoseries glycolipids.
Four other genes involved in these different biosyntheses were found in cluster 3 (Figure 3). They encoded two other fucosyltransferases, a sialyltransferase and a galactosyltransferase. The sialyltransferase is involved in ganglioside synthesis, while the three other enzymes are required for lacto and/or neo-lactoseries glycolipid biosynthesis. For glycoproteins, three genes in cluster 3 were revealed: Galnt5 and Galnt6 encoded O-glycan synthesis proteins and St8sia2 a sialyltransferase involved in the biosynthesis of Ncam 1 polysialic acid (PSA). The latter bears polysialylated $N$-glycans and mucin type $O$-glycans on a musclespecific domain which is involved in myoblast fusion 


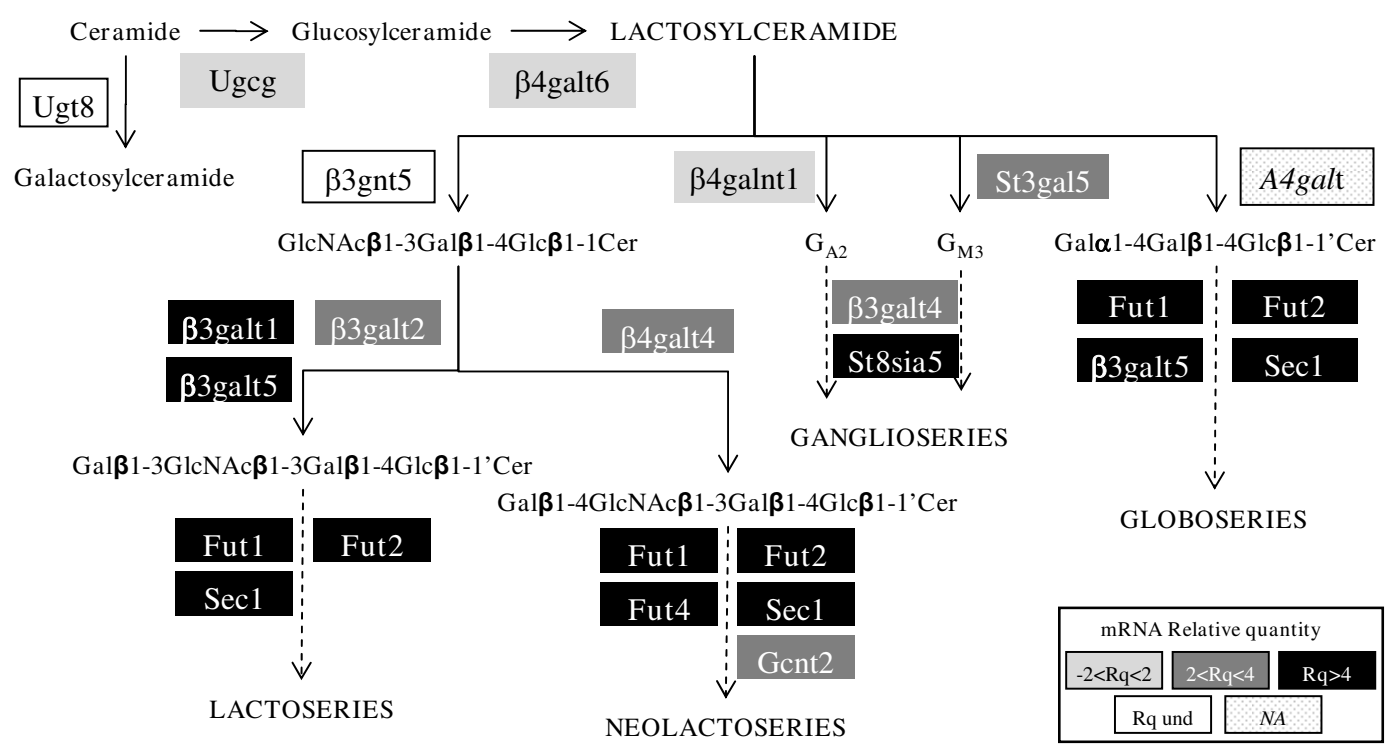

\section{Figure 4}

Schematic representation of glycosphingolipid synthesis pathways. The enzymes responsible for the main steps of glycosphingolipid biosynthesis are indicated. The expression levels (relative quantity of mRNA) of the corresponding genes are reported. NA: Not Analyzed; Rq: Relative quantity; Und: Undetermined.

[24]. The up-regulation of these three genes was in good agreement with the findings of the previous study. Therefore, myoblast fusion may require some glycosphingolipid rearrangements and/or terminal modifications (as fucosylation and sialylation) to glycans of membrane glycoproteins and glycolipids.

\section{$G_{M 3}$ ganglioside levels increase in differentiating $\mathrm{C} 2 \mathrm{CI}$ cells}

In order to confirm some of these membrane glycoconjugate rearrangements, glycolipids were considered for further analyses. According to their metabolic pathways and gene expression patterns, lactosylceramid seemed to be preferentially synthesized when compared to galactosylceramid (Figure 4). Indeed, the Ugt8 gene was weakly expressed (Ct>33), while the Ugcg and $\beta 4$ galt 6 genes were strongly expressed $(\mathrm{Ct}<25)$. Lactosylceramid is the common precursor of four biosynthesis pathways. The expression levels of the analyzed genes implicated in these pathways indicated that some compounds could be preferentially synthesized and/or reshaped. Among these, only $\mathrm{G}_{\mathrm{M} 3}$ (and its derivatives) could be enhanced because the St3gal5, $\beta 3$ GalT4 and St8sia5 genes were up-regulated (Figure 4). In order to test this hypothesis, immuno-cytostaining was used to analyze $\mathrm{G}_{\mathrm{M} 3}$ gangliosides on differentiating myoblasts (Figure 5). Only a few myoblasts are positively stained at $0 \mathrm{~h}$ and $12 \mathrm{~h}$ of differentiation. Beyond $24 \mathrm{~h}$, the immunostaining increased, and most of the cells were stained at $48 \mathrm{~h}$ and $72 \mathrm{~h}$. This result showed that levels of $\mathrm{G}_{\mathrm{M} 3}$ indeed increased in the plasma mem- brane during the onset of $\mathrm{C} 2 \mathrm{C} 12$ differentiation. Interestingly, beyond 48-72 $\mathrm{h}$ of differentiation, cells with stronger staining were mostly elongated and underwent differentiation, which argues for a role of $\mathrm{G}_{\mathrm{M} 3}$ in $\mathrm{C} 2 \mathrm{C} 12$ differentiation and fusion.

\section{Conclusion}

Little is known about the importance of glycosylation in myogenesis because of the poor representativeness of glycogenes, i.e. $2 \%$ of the genome, and because the weak expression of most of them is not revealed by microarrays. In order to determine how glycosylation could be involved in this process, we used a quantitative real-time RT-PCR technology to analyze the expression of 375 glycogenes representing more than $60 \%$ of the mouse glycogenome, during the onset of differentiation of the myogenic $\mathrm{C} 2 \mathrm{C} 12$ cell line. The glycogenome includes genes encoding for proteins involved in the transport, synthesis and/or recognition of monosaccharide precursors, glycans and glycoconjugates. This study presents for the first time a focused transcriptomic analysis of the glycogenome during myogenic differentiation.

Around $75 \%$ of the glycogenes thus analyzed was expressed, one third being deregulated by at least 2-fold, showing the importance of glycosylation in this process. Among these deregulated genes, 37 were modified more than 4 -fold. Most of these genes (29 genes) had never been associated with myogenesis before. The functions of these 37 glycogenes suggested new roles for glycoconju- 


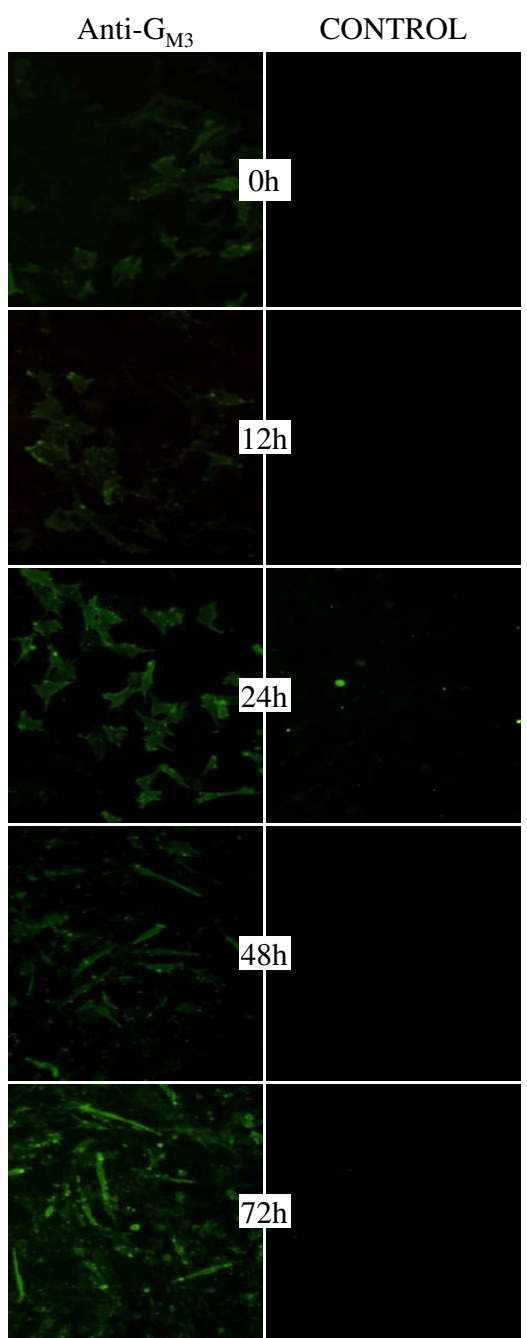

Figure 5

$\mathbf{G}_{M 3}$ ganglioside staining in differentiating $\mathbf{C 2} \mathrm{CI} 2$ cells. Cells were labeled with an anti- $\mathrm{G}_{\mathrm{M3}}$ antibody. This primary antibody was detected by a secondary antibody coupled to FITC. Isotypic controls for each differentiation time point are given.

gates in myogenic differentiation (Figure 6). The initiation of $\mathrm{C} 2 \mathrm{C} 12$ differentiation may require specific cell signaling mediated by glycans such as PPAR, and Notch signaling. At the same time, a modification to ECM composition may occur by means of a switch of keratan sulfate GAG to heparan sulfate GAG, in order to promote cell differentiation. Initiation may be followed by the reshaping of membrane glycoconjugates such as cell adhesion molecules, glycolipids and glycoproteins, in order to prepare cells for fusion into myotubes. The lag time in expression between genes encoding CAMs and genes encoding glycolipid synthesis proteins suggests that cell interactions precede membrane glycolipid rearrangements. Finally, initial myotube maturation in late-appearing myofibers involves various intracellular processes dependent on glycosylation. Indeed, a variety of cell functions are associated with proteins encoded by some markedly upregulated genes. Some of these sugar carriers (GLUT4 and GLUT5) have already been associated with myogenesis [53-55]. Other functions, such as glucose transport by GLUT6 [56], exocytosis by tetranectin (CLEC3b) [57], or the non-lysosomal catabolic pathway by Klotho-related protein (KLrP or LCTL) [58] are suggested by these transcriptional data. Thus, this screening of glycogenome expression provides clues to a clearer understanding of certain stages in myogenesis.

\section{Methods \\ Biological materials}

C2C12 mouse myoblasts (strain C3H, American Type Culture Collection (ATCC), Manassas, VA, USA) were cultured in DMEM (Dubelco's modified Eagle's medium, Eurobio, Courtaboeuf, France) supplemented with 10\% fetal calf serum (Eurobio), $2 \mathrm{mM}$ L-glutamine, 50 units/ $\mathrm{mL}$ penicillin and $50 \mu \mathrm{g} / \mathrm{mL}$ streptomycin. Cells were grown to $80 \%$ confluence and were differentiated into myotubes with DMEM supplemented with 2\% horse serum. After $48 \mathrm{~h}$ of differentiation, the medium was changed every day. For each kinetic point analyzed, cells were rinsed briefly with PBS and harvested following trypsinization ( $1 \times$ PBS, $1 \mathrm{mM}$ EDTA, 0.05\% (w/v) trypsin).

\section{RNA extraction and CDNA synthesis}

Total RNA from each sample was obtained by anion exchange chromatography (RNeasy mini Kit, Qiagen Inc., Hilden, Germany). The integrity and quantity of total RNA were measured using a micro fluidic-based platform (Agilent 2100 Bioanalyser, Agilent Technologies Inc., Santa Clara, CA, USA). The High Capacity cDNA Archive Kit (Applied Biosystems, Foster City, CA, USA) was used to convert 5 or $10 \mu \mathrm{g}$ of total RNA into single-stranded cDNA.

\section{Design of the glycogenome TaqMan Low Density Array (TLDA)}

A micro-fluidic card dedicated to quantitative real-time RT-PCR analyses of part of the mouse genome, the 'glycogenome', was designed. The glycogenes thus analyzed encode proteins involved in glycan synthesis or glycan recognition. They were selected from GenBank, CAZY and MGI databases [59-61]. They include glycosidases, glycosyltransferases, sugar carriers and sugar metabolism proteins, translocases, sulfotransferases and lectins. These genes control glycosylation functions which likely regulate myogenesis. When this work started, 600 corresponding murine genes were listed (Table 1). The TLDA technology used is based on quantitative real-time RT- 


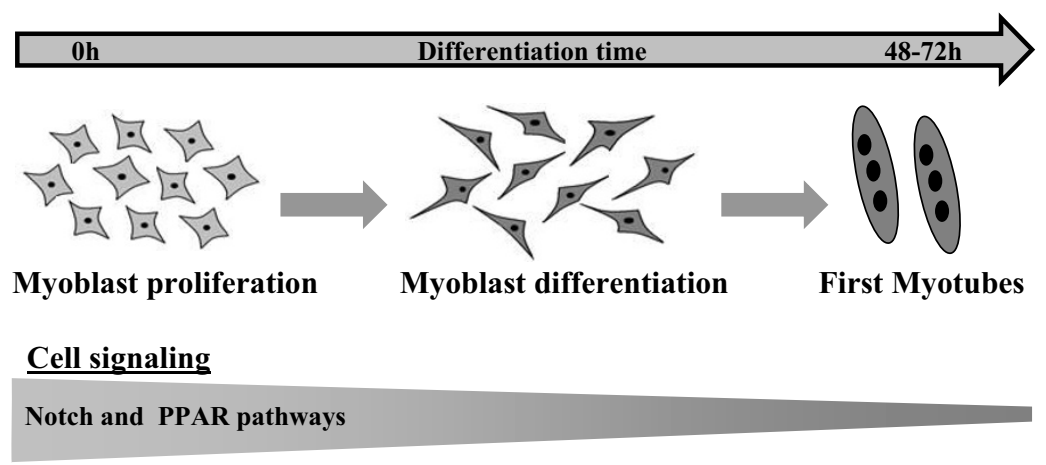

\begin{tabular}{l} 
ECM sulfation reshaping \\
\hline Keratan sulfate GAG \\
\hline
\end{tabular}

\begin{tabular}{|c|c|}
\hline & Itg $\alpha 4$ and $\alpha 7$, Lgals 7 and 12, Neam 1 \\
\hline \multicolumn{2}{|l|}{ Itg $\alpha 3$, Itg $\beta 7$, Siglecg, Selp } \\
\hline & $\mathrm{G}_{\mathrm{M} 3}$, neo- and lactoseries \\
\hline
\end{tabular}

Myotube maturation

Sugar carriers, intracellular reshaping proteins

\section{Figure 6}

Hypothetical model of biological processes dependent on highly regulated glycogenes during $\mathrm{C} 2 \mathrm{CI} 2$ cell differentiation. On the basis of protein functions encoded by highly regulated glycogenes, four biological and molecular processes are proposed for their implication in $\mathrm{C} 2 \mathrm{Cl} 2$ myoblast differentiation.

PCR with TaqMan probes validated by the manufacturer. Among the 600 genes listed, only 389 validated probes were available for gene expression studies https://prod ucts.Appliedbiosystems.com/ab/en/US/adirect/ab. The technology operates on 384 well plates and allows a simultaneous analysis of 375 candidate glycogenes, 9 wells being dedicated to 6 reference genes. Consequently, among the 389 genes, for which validated probes were available, some sulfotransferase genes were not selected in order to preferentially analyze all available genes involved in glycan biosynthesis and not in glycan modification. Thus, for genes encoding sulfotransferases, only 22 probes of the 36 listed were considered (Table 1), reducing to 375 the number of glycogenes analyzed using TLDA, that is $\sim 60 \%$ of the mouse genes known to be related to glycosylation.

\section{Quantitative real-time RT-PCR}

The quantity of each mRNA was determined by quantitative real-time RT-PCR on an ABI Prism 7900 Sequence Detector System using TaqMan probe-based chemistry
(Applied Biosystems). 6-carboxyfluorescein (FAM) was used as a reporter. The amplification reactions for each gene were performed with 2 ng cDNA for 96-well plates (analysis of myogenic markers) and with $3 \mathrm{ng}$ cDNA for TaqMan Low Density Arrays (TLDA) (analysis of glycogenes). This relative quantification was reliant on the use of several reference genes: $18 S$ RNA, GGpdx, Gapdh, Tcea, Tbp.

\section{Data analysis}

Gene mRNA expression data were collected and analyzed using SDS 2.2.2 software (Applied Biosystems). The comparative $\Delta \Delta \mathrm{Ct}$ method was used to quantify the relative abundance of mRNA. This method uses a calibrator sample to enable a comparison of gene expression levels in different samples. During this study, we used time $\mathrm{t}=0 \mathrm{~h}$ of differentiation as the calibrator sample. The values obtained indicated the changes in expression in the sample of interest by comparison with the calibrator sample after normalization to $18 \mathrm{~S}$ RNA. Relative quantities were regarded as significant for genes whose Ct (Threshold 
Cycle) was lower than 33. Genes that were not expressed were given a Ct value of 40 by default.

Relative levels of mRNA in the 37 selected genes were logtransformed and analyzed using Principal Component Analysis (PCA) and hierarchical cluster analysis (HCA) with PAST version $1.78[62,63]$ in order to reveal trends in their expression. This mathematical procedure reduces the number of possibly correlated variables (seven dimensions corresponding to the different differentiation times) to a smaller number. Thus, most of the data are projected in a 2D-space defined by the two principal components PC1 and PC2, which are synthetic axes expressing the percentage of data variance. Indeed, PCA extracts the direction where the cloud of values is extended, constituting the first component or principal component (PC1). The next direction (PC2) is orthogonal to the first one. The cloud of points reflects the level of expression of each gene as a function of its position relative to the vectors. Vectors indicate the orientation of variation and correspond to most representative expression profiles. Samples belonging to a same pattern are therefore expected to be grouped in a similar area. The coordinates of each gene on the ordination plan were used to calculate Euclidean distances between all pair-wise combinations. The unweighted pairgroup average was taken as an agglomeration method to construct the Hierarchical Component Analysis.

\section{Immuno-cyto-chemistry}

$\mathrm{C} 2 \mathrm{C} 12$ cells were grown on glass cover-slips. After removing the medium, the cells were washed twice with PBS and fixed for $15 \mathrm{~min}$ in $4 \%$ paraformaldehyde. After two washes of 5 min each in $1 \times$ PBS, the cells were further incubated for $1 \mathrm{~h}$ with a blocking solution (1× PBS with $10 \%$ fetal bovine serum (Eurobio)), and labeled with an anti- $\mathrm{G}_{\mathrm{M} 3}$ primary antibody (Seikagaku Corporation, Japan) diluted $1 / 100$ in blocking solution for $1 \mathrm{~h}$ at room temperature. A control was performed using cells incubated with a mouse isotypic IgM (Santa Cruz, CA, USA) at the same concentration as the anti- $\mathrm{G}_{\mathrm{M} 3}$ primary antibody. The cells were rinsed in $1 \times \mathrm{PBS}$, incubated for $1 \mathrm{~h}$ with an FITC-conjugated secondary antibody (Sigma-Aldrich, Saint Quentin Fallavier, France) and then washed 3 times for 5 min with $1 \times$ PBS. The cover-slips were washed in PBS and mounted on glass slides. The cells were then observed under an Olympus epifluorescence microscope.

\section{Abbreviations}

CAM: Cell Adhesion Molecule; ECM: ExtraCellular Matrix; GAG: GlycosAminoGlycan; HCA: Hierarchical Cluster Analysis; Itg: Integrin; LIM: protein containing a cystein-rich domain described in Lin-11, Il-1 and Mec-3 proteins; MRF: Myogenic Regulatory Factor; Ncam: Neural cell adhesion molecule; PCA: Principal Component
Analysis; PPAR: Peroxysome Proliferator-Activated Receptor.

\section{Authors' contributions}

MJ carried out cell cultures, mRNA extractions, RT-PCR quantification, immuno-cyto chemistry experiments, participated in data exploitation and was involved in drafting and critically revising the manuscript. AA contributed to the acquisition and interpretation of data concerning validation of the model, to drafting corresponding paragraphs in the manuscript and its critical revision. CL participated in critical revision of the manuscript. AG was involved in interpreting the data and in critical revision of the manuscript. AM participated in the design of experiments, the interpretation of data, drafting and critical revision of the manuscript. FD participated in the design of experiments, the design of glycogene arrays, and the performance of statistical data analyses, data interpretation, drafting the manuscript and its critical revision. All authors have read and have given their final approval of the manuscript.

\section{Additional material}

\section{Additional file 1}

List of glycogenes analyzed by quantitative RT-PCR. This table presents the list of glycogenes analyzed by TLDA (TaqMan Low Density Array) according to their protein function and family. Their symbol, name, NCBI identification and Applied Biosystems identification (Assay ID) are given. Click here for file

[http://www.biomedcentral.com/content/supplementary/14712164-10-483-S1.XLS]

\section{Additional file 2}

Results of glycogenes mRNA quantification during C2C12 differentiation. This table presents the threshold Cycle (Ct) and Relative Quantification $(R Q)$ values of reference gene and glycogenes for each time course point of $\mathrm{C} 2 \mathrm{C} 12$ differentiation. The calibrator sample corresponds to time $0 \mathrm{~h}$ of differentiation and the normalization gene to 18S. AV: Aberrant Value; ND: Not Determined.

Click here for file

[http://www.biomedcentral.com/content/supplementary/14712164-10-483-S2.XLS]

\section{Acknowledgements}

This work was supported by the Limousin Regional Council, and the French Ministry of Research and Technology doctoral fellowships of M. Janot and A. Audfray.

\section{References}

I. Buckingham M, Bajard L, Chang T, Daubas P, Hadchouel J, Meilhac S, Montarras D, Rocancourt D, Relaix F: The formation of skeletal muscle: from somite to limb. J Anat 2003, 202:59-68.

2. Tapscott SJ: The circuitry of a master switch: Myod and the regulation of skeletal muscle gene transcription. Development 2005, 132:2685-2695. 
3. Naya FJ, Olson E: MEF2: a transcriptional target for signaling pathways controlling skeletal muscle growth and differentiation. Curr Opin Cell Biol 1999, I I:683-688.

4. Rudnicki MA, Jaenisch R: The MyoD family of transcription factors and skeletal myogenesis. Bioessays 1995, 17:203-209.

5. Black BL, Olson EN: Transcriptional control of muscle development by myocyte enhancer factor-2 (MEF2) proteins. Annu Rev Cell Dev Biol 1998, I 4:167-196.

6. Murre C, McCaw PS, Vaessin H, Caudy M, Jan LY, Jan YN, Cabrera CV, Buskin JN, Hauschka SD, Lassar AB, et al.: Interactions between heterologous helix-loop-helix proteins generate complexes that bind specifically to a common DNA sequence. Cell 1989, 58:537-544.

7. Lassar AB, Davis RL, Wright WE, Kadesch T, Murre C, Voronova A, Baltimore $\mathrm{D}$, Weintraub $\mathrm{H}$ : Functional activity of myogenic HLH proteins requires hetero-oligomerization with EI2/ E47-like proteins in vivo. Cell |99|, 66:305-315.

8. Blackwell TK, Weintraub $\mathrm{H}$ : Differences and similarities in DNA-binding preferences of MyoD and E2A protein complexes revealed by binding site selection. Science 1990, 250: II04-1110.

9. Meissner JD, Umeda PK, Chang KC, Gros G, Scheibe RJ: Activation of the beta myosin heavy chain promoter by MEF-2D, MyoD, p300, and the calcineurin/NFATcl pathway. J Cell Physiol 2007, 2II:138-148.

10. Kang JS, Mulieri PJ, Hu Y, Taliana I L, Krauss RS: BOC, an Ig superfamily member, associates with CDO to positively regulate myogenic differentiation. The EMBO Journal 2002, 2 I: I I4-I 24.

II. Kang JS, Yi MJ, Zhang W, Feinleib JL, Cole F, Krauss RS: Netrins and neogenin promote myotube formation. J Cell Biol 2004, 167:493-504.

12. Cuenda $A$, Cohen $P$ : Stress-activated protein kinase-2/p38 and a rapamycin-sensitive pathway are required for $\mathrm{C} 2 \mathrm{Cl} 2 \mathrm{myo-}$ genesis. J Biol Chem 1999, 274:434I-4346.

13. Moran JL, Li Y, Hill AA, Mounts WM, Miller CP: Gene expression changes during mouse skeletal myoblast differentiation revealed by transcriptional profiling. Physiol Genomics 2002, 10:103-111.

14. Shen X, Collier JM, Hlaing M, Zhang L, Delshad EH, Bristow J, Bernstein HS: Genome-wide examination of myoblast cell cycle withdrawal during differentiation. Dev Dyn 2003, 226: $128-138$.

15. Delgado I, Huang X, Jones S, Zhang L, Hatcher R, Gao B, Zhang P: Dynamic gene expression during the onset of myoblast differentiation in vitro. Genomics 2003, 82:109-121.

16. Tomczak KK, Marinescu VD, Ramoni MF, Sanoudou D, Montanaro F, Han M, Kunkel LM, Kohane IS, Beggs AH: Expression profiling and identification of novel genes involved in myogenic differentiation. FASEB J 2004, I 8:403-405.

17. Puente LG, Carrière JF, Kelly JF, Megeney LA: Comparative analysis of phosphoprotein-enriched myocyte proteomes reveals widespread alterations during differentiation. FEBS Lett 2004, 574: $138-144$.

18. Kislinger T, Gramolini AO, Pan Y, Rahman K, MacLennan DH, Emili A: Proteome dynamics during $\mathrm{C} 2 \mathrm{CI} 2$ myoblast differentiation. Mol Cell Proteomics 2005, 4:887-90I.

19. Osses N, Brandan E: ECM is required for skeletal muscle differentiation independently of muscle regulatory factor expression. Am J Physiol Cell Physiol 2002, 282:C383-394.

20. Cornelison DD, Wilcox-Adelman SA, Goetinck PF, Rauvala H, Rapraeger AC, Olwin BB: Essential and separable roles for Syndecan-3 and Syndecan-4 in skeletal muscle development and regeneration. Genes Dev 2004, I 8:223I-2236.

21. Olden K, Law J, Hunter VA, Romain R, Parent JB: Inhibition of fusion of embryonic muscle cells in culture by tunicamycin is prevented by leupeptin. J Cell Biol I98I, 88: 199-204.

22. Metzler M, Gertz A, Sarkar M, Schachter H, Schrader JW, Marth JD: Complex asparagine-linked oligosaccharides are required for morphogenic events during post-implantation development. EMBO J 1994, I 3:2056-2065.

23. Fazeli S, Wells DJ, Hobbs C, Walsh FS: Altered secondary myogenesis in transgenic animals expressing the neural cell adhesion molecule under the control of a skeletal muscle alpha-actin promoter. J Cell Biol 1996, I35:24I-25I.

24. Suzuki M, Angata K, Nakayama J, Fukuda M: Polysialic acid and mucin type O-glycans on the neural cell adhesion molecule differentially regulate myoblast fusion. J Biol Chem 2003, 278:49459-49468.

25. Fukumoto $S$, Iwamoto $T$, Sakai E, Yuasa K, Fukumoto E, Yamada $A$, Hasegawa T, Nonaka K, Kato Y: Current topics in pharmacolog. ical research on bone metabolism: osteoclast differentiation regulated by glycosphingolipids. J Pharmacol Sci 2006, 100:195-200.

26. Yanagisawa $M, Y u$ RK: The expression and functions of glycoconjugates in neural stem cells. Glycobiology 2007, 17:57R-74R.

27. Leskawa KC, Hogan EL: Regulation of glycolipid synthesis during differentiation of clonal murine muscle cells. Mol Cell Biochem 1990, 96:163-173.

28. Cambron LD, Leskawa KC: Glycosphingolipids during skeletal muscle cell differentiation: comparison of normal and fusiondefective myoblasts. Mol Cell Biochem 1994, 130:173-185.

29. Ornatsky OI, McDermott JC: MEF2 protein expression, DNA binding specificity and complex composition, and transcriptional activity in muscle and non-muscle cells. J Biol Chem 1996, 27 I:24927-24933.

30. Kong Y, Flick MJ, Kudla AJ, Konieczny SF: Muscle LIM protein promotes myogenesis by enhancing the activity of MyoD. Mol Cell Biol 1997, I7:4750-4760.

31. Cossins J, Vernon AE, Zhang Y, Philpott A, Jones PH: Hes6 regulates myogenic differentiation. Development 2002, I 29:2195-2207.

32. Shimokawa T, Kato M, Ezaki O, Hashimoto S: Transcriptional regulation of muscle-specific genes during myoblast differentiation. Biochem Biophys Res Commun 1998, 246:287-292.

33. Dedieu S, Mazeres G, Cottin P, Brustis JJ: Involvement of myogenic regulator factors during fusion in the cell line C2CI 2. Int J Dev Biol 2002, 46:235-24I.

34. Provenzano M, Mocellin S: Complementary techniques: validation of gene expression data by quantitative real time PCR. Adv Exp Med Biol 2007, 593:66-73.

35. Bai KJ, Spicer AP, Mascarenhas MM, Yu L, Ochoa CD, Garg HG, Quinn DA: The role of hyaluronan synthase 3 in ventilatorinduced lung injury. Am J Respir Crit Care Med 2005, 172:92-98.

36. Farmery MR, Allen S, Allen AJ, Bulleid NJ: The role of ERp57 in disulfide bond formation during the assembly of major histocompatibility complex class I in a synchronized semipermeabilized cell translation system. J Biol Chem 2000, 275: 14933-14938.

37. Anastasia L, Papini N, Colazzo F, Palazzolo G, Tringali C, Dileo L, Piccoli M, Conforti E, Sitzia C, Monti E, Sampaolesi M, Tettamanti G, Venerando B: NEU3 sialidase strictly modulates GM3 levels in skeletal myoblasts $\mathrm{C} 2 \mathrm{CI} 2$ thus favoring their differentiation and protecting them from apoptosis. J Biol Chem 2008, 283:36265-36271.

38. Prados B, Peña A, Cotarelo RP, Valero MC, Cruces J: Expression of the murine Pomtl gene in both the developing brain and adult muscle tissues and its relationship with clinical aspects of Walker-Warburg syndrome. Am J Pathol 2007, I70:1659-1668

39. Brun RP, Kim JB, Hu E, Altiok S, Spiegelman BM: Adipocyte differentiation: a transcriptional regulatory cascade. Curr Opin Cell Biol 1996, 8:826-832.

40. Gregoire FM, Smas CM, Sul HS: Understanding adipocyte differentiation. Physiol Rev 1998, 78:783-809.

41. Chui PC, Guan HP, Lehrke M, Lazar MA: PPARgamma regulates adipocyte cholesterol metabolism via oxidized LDL receptor I. J Clin Invest 2005, I I 5:2244-2256.

42. Moran JL, Johnston SH, Rauskolb C, Bhalerao J, Bowcock AM, Vogt TF: Genomic structure, mapping, and expression analysis of the mammalian Lunatic, Manic, and Radical fringe genes. Mamm Genome 1999, 10:535-541.

43. Haines N, Irvine KD: Glycosylation regulates Notch signalling. Nat Rev Mol Cell Biol 2003, 4:786-797.

44. Johnston SH, Rauskolb C, Wilson R, Prabhakaran B, Irvine KD, Vogt TF: A family of mammalian Fringe genes implicated in boundary determination and the Notch pathway. Development 1997, 1 24:2245-2254

45. Buas MF, Kabak S, Kadesch T: Inhibition of myogenesis by Notch: evidence for multiplepathways. J Cell Physiol 2009, 218:84-93. 
46. Yang RY, Hsu DK, Yu L, Chen HY, Liu FT: Galectin- I 2 is required for adipogenic signaling and adipocyte differentiation. J Biol Chem 2004, 279:2976I-29766.

47. Handel TM, Johnson Z, Crown SE, Lau EK, Proudfoot AE: Regulation of protein function by glycosaminoglycans--as exemplified by chemokines. Annu Rev Biochem 2005, 74:385-4I0.

48. Funderburgh JL, Mitschler RR, Funderburgh ML, Roth MR, Chapes SK, Conrad GW: Macrophage receptors for lumican. A corneal keratan sulfate proteoglycan. Invest Ophthalmol Vis Sci 1997, 38: II59-1167.

49. Fukushi J, Makagiansar IT, Stallcup WB: NG2 proteoglycan promotes endothelial cell motility and angiogenesis via engagement of galectin-3 and alpha3betal integrin. Mol Biol Cell 2004 I 5:3580-3590.

50. Brancaccio M, Guazzone S, Menini N, Sibona E, Hirsch E, De Andrea $M$, Rocchi M, Altruda F, Tarone G, Silengo L: Melusin is a new muscle-specific interactor for beta(I) integrin cytoplasmic domain. J Biol Chem 1999, 274:29282-29288.

51. Schöber S, Mielenz D, et al.: The Role of Extracellular and Cytoplasmic Splice Domains of [alpha]7-Integrin in Cell Adhesion and Migration on Laminins. Experimental Cell Research 2000 , 255:303-3।3.

52. Blanco-Bose WE, Blau HM: Laminin-induced change in conformation of preexisting alpha7betal integrin signals secondary myofiber formation. Dev Biol 200।, 233:|48-I60.

53. Stuart CA, Yin D, Howell ME, Dykes RJ, Laffan JJ, Ferrando AA: Hexose transporter mRNAs for GLUT4, GLUT5, and GLUTI2 predominate in human muscle. Am J Physiol Endocrinol Metab 2006, 29I:EI067-EI073.

54. Im SS, Kwon SK, Kim TH, Kim HI, Ahn YH: Regulation of glucose transporter type 4 isoform gene expression in muscle and adipocytes. IUBMB Life 2007, 59:| 34-|45.

55. Hajduch E, Litherland G], Turban S, Brot-Laroche E, Hundal HS: Insulin regulates the expression of the GLUT5 transporter in L6 skeletal muscle cells. FEBS Lett 2003, 549:77-82.

56. Lisinski I, Schürmann A, Joost HG, Cushman SW, Al-Hasani H: Targeting of GLUT6 (formerly GLUT9) and GLUT8 in rat adipose cells. Biochem J 200I, 358:517-522.

57. Clemmensen I: Interaction of tetranectin with sulphated polysaccharides and trypan blue. Scand J Clin Lab Invest 1989, 49:719-725

58. Hayashi $Y$, Okino N, Kakuta $Y$, Shikanai T, Tani M, Narimatsu H, Ito $\mathrm{M}$ : Klotho-related protein is a novel cytosolic neutral betaglycosylceramidase. J Biol Chem 2007, 282:30889-30900.

59. GenBank [http://www.ncbi.nlm.nih.gov/Genbank/]

60. The CAZy database [http://www.cazy.org/]

61. The Mouse Genome Informatics [http://www.informat ics.jax.org]

62. Hammer O, Harper DAT, Ryan PD: PAST: Paleontological Statistics Software Package for Education and Data Analysis. Palaeontologia Electronica 2001, 4:9.

63. The Paleontological Statistics Software Package for Education and Data Analysis [http://folk.uio.no/ohammer/past/down load.html]

64. The Kegg Pathway Database [http://www.genome.ad.jp/kegg/ pathway.html]
Publish with Bio Med Central and every scientist can read your work free of charge

"BioMed Central will be the most significant development for disseminating the results of biomedical research in our lifetime. "

Sir Paul Nurse, Cancer Research UK

Your research papers will be:

- available free of charge to the entire biomedical community

- peer reviewed and published immediately upon acceptance

- cited in PubMed and archived on PubMed Central

- yours - you keep the copyright
BioMedcentral 